\title{
Sıcak-Dövme Döküm Malzemelerin Performans Özelliklerini İyileştirmeye Yönelik Kaplama Koşullarının Karşılaştırılması
}

\author{
Adife Şeyda Yargıç ${ }^{1 *}$, Bünyamin Eren², Nurgül Özbay ${ }^{3}$ \\ 1* Bilecik Şeyh Edebali Üniversitesi, Mühendislik Fakültesi, Kimya Mühendisliği Bölümü, Bilecik, Türkiye (ORCID: 0000-0002-8671-5896), \\ seyda.guler@bilecik.edu.tr \\ ${ }^{2}$ Uzman Kataforez Yüzey Kaplama San. ve Tic. A.Ş., Bursa, Türkiye (ORCID: 0000-0002-5109-1462), bunyamineren@uzmankataforez.com.tr \\ ${ }^{3}$ Bilecik Şeyh Edebali Üniversitesi, Mühendislik Fakültesi, Kimya Mühendisliği Bölümü, Bilecik, Türkiye (ORCID: 0000-0002-0666-3417), \\ nurgul.ozbay@bilecik.edu.tr
}

(İlk Geliş Tarihi 7 Aralık 2020 ve Kabul Tarihi 31 Ocak 2021)

(DOI: 10.31590/ejosat.836802)

\begin{abstract}
ATIF/REFERENCE: Yargıç, A.Ş., Eren, B. \& Özbay, N. (2021). Sıcak-Dövme Döküm Malzemelerin Performans Özelliklerini İyileştirmeye Yönelik Kaplama Koşullarının Karşılaştırılması. Avrupa Bilim ve Teknoloji Dergisi, (21), 506-517.

$\ddot{O} \mathbf{z}$

Bu çalı̧̧manın amacı, otomotiv sektöründe yaygın olarak kullanılan iki adet sıcak-dövme döküm malzeme (F899 ve F990) üzerine ekonomik iki tür kaplamanın ( $\mathrm{Zn+kataforez)} \mathrm{birlikte} \mathrm{uygulanması} \mathrm{ile} \mathrm{düşük} \mathrm{mikronlarda,} \mathrm{korozyon} \mathrm{performansı} \mathrm{yüksek} \mathrm{döküm}$ parçalar üretilmesidir. Çalışma kapsamında, F899 ve F990 üzerine öncelikle alkali Zn/Zn-Fe/Zn-Ni, asitli Zn/Zn-Ni ortamda 12-15 $\mu \mathrm{m}$ çinko kaplama, ardından 20-25 $\mu \mathrm{m}$ kataforez kaplama yapılmıştır. Sıcak-dövme döküm parçaların karakterize edilmesi amacıyla mürekkep, hogabom, şok, pull-off adhezyon, su direnci, tuz sisi, taş çarpma, çevrimsel korozyon ve scab korozyon performansı testleri uygulanmıştır. Ayrıca, $\mathrm{x}-1$ şını kırınım laminografi (xdl) cihazında Zn kaplama kalınlık ölçümü yapılmış ve taramalı elektron mikroskobunda da fosfat kristal görünümü alınmıştır. Pull-off adhezyon testinde, malzemelerin 263-493 psi aralığında değişen kopma mukavemetine sahip oldukları belirlenmiş̧tir. Sıcak-dövme döküm malzemelerin karakterizasyon sonuçlarına göre; alkali $\mathrm{Zn} / \mathrm{Zn}$ $\mathrm{Fe} / \mathrm{Zn}-\mathrm{Ni}$ kaplamalar üzerine kataforez kaplamanın istenilen performans ve korozyon dayanımı sağlamadığı; ancak asitli $\mathrm{Zn} / \mathrm{Zn}-\mathrm{Ni}$ kaplamalar üzerine kataforez kaplanan malzemelerin uygun korozyon performansı sağladığı belirlenmiştir. Sonuç olarak, kaplama şartları değiştirilerek istenilen özelliklerde düşük maliyetli kaplama işleminin gerçekleştirilebileceği ispatlanmıştır.
\end{abstract}

Anahtar Kelimeler: Alkali/asitli çinko kaplama, Kataforez kaplama, Korozyon performansı, Sıcak-dövme döküm malzemeler.

\section{Comparison of Coating Conditions for Improving Performance Properties of Hot-Forged Casting Materials}

\begin{abstract}
This study aims to produce cast parts with high corrosion performance at low micron by applying two types of economical coatings (zinc+cataphoresis) on two hot-forged cast materials (F899 and F990) widely used in the automotive industry. Within the scope of the study, 12-15 $\mu \mathrm{m}$ zinc coating in alkaline Zn/Zn-Fe/Zn-Ni, acidic Zn/Zn-Ni was applied on F899 and F990, followed by 20-25 $\mu \mathrm{m}$ cataphoresis coating. In order to characterize hot-forged cast parts, ink, hogabom, shock, pull-off adhesion, water resistance, salt fog, stone impact, cyclic corrosion, and scab corrosion performance tests were applied. Besides, Zn coating thickness was measured in the $\mathrm{x}$-ray diffraction laminography (xdl) device, and phosphate crystal images were obtained in the scanning electron microscope. In the pull-off adhesion test, it was determined that the materials had a tensile strength ranging from 263-493 psi. According to the characterization results of hot-forged cast materials; it was determined that cataphoresis coating on the alkaline $\mathrm{Zn} / \mathrm{Zn}-\mathrm{Fe} / \mathrm{Zn}-\mathrm{Ni}$ coatings did not provide the desired performance and corrosion resistance, but materials coated with cataphoresis on the acidic $\mathrm{Zn} / \mathrm{Zn}$ $\mathrm{Ni}$ coatings provided appropriate corrosion performance. As a result, it has been proven that low-cost coating can be achieved with desired properties by changing the coating conditions.
\end{abstract}

Keywords: Alkaline/acidic zinc coating, Cataphoresis coating, Corrosion performance, Hot-forged cast materials.

* Sorumlu Yazar: seyda.guler@bilecik.edu.tr 


\section{Giriş}

Kataforez kaplama otomotiv ana sanayisinde ilk kat (astar) olarak metal yüzeye uygulanmaktadır. Bununla beraber kataforez kaplama otomotiv yan sanayilerinin gelişmesiyle birlikte yaygınlaşmış olup, fason üretim olarak da çeşitli hacim boyutlarında ( 1 ton-500 ton) çalışılmaktadır. 2000'li yıllardan sonra, otomotiv sektörü dışında beyaz eşya, mobilya, savunma, genel endüstri, tarım ekipmanları gibi sanayilerde de kataforez kaplama aktif olarak her geçen gün kapasite arttırılarak kullanılmaya başlanmıştır. Bu kaplama yöntemi metal parçaları korozyona karşı korumada en etkili sistem olmakla beraber parça ömrünün de uzamasını sağlamaktadır (Lawrance, 1963).

Çinko kaplamalar, birçok yapısal ve genel mühendislik uygulamalarında malzemelerin korozyondan korunması için sıklıkla kullanılmaktadır. Bu kaplamalar iyi bir korozyon direnci göstermesinin yanı sıra malzeme üzerinde iyi mekanik özellikler göstermekte, kaynak yapılmasına olanak sağlamakta ve boyanabilmektedir. Öte yandan, yüksek çözünme hızı çinko kaplamaların kullanımını kısıtlamaktadır. Çinko kaplamaların kullanım ömrü, fosfatlama, üç değerlikli krom pasivasyonu ve silisleme prosesleri gibi pasivasyon süreçleri ile uzatılabilmektedir. Çinko korozyon dirençlerinin özellikleri; Ni, $\mathrm{Co}, \mathrm{Sn}$ ve $\mathrm{Cr}$ gibi geçiş metalleriyle birlikte alaşımlandırılarak önemli ölçüde iyileştirilebilmektedir (Ganesan vd., 2014; Zaki, 1993).

Döküm parçalar yüksek akım verimli elektrolitik asitli çinko kaplamalar ile kaplanabilmektedir, ancak asitli çinko kaplamaların korozyon dirençleri alkali çinko kaplamalardan daha düşüktür. Yılmaz (2013) yaptığı çalışmada, döküm ve zamak parçalar üzerine hem akım verimi hem de korozyon dayanımı yüksek bir kaplama yapmayı amaçlamıştır. Elektronegativite farkından dolayı; yapısında ağırlıkça \%12-16 arasında nikel içeren çinko nikel alaşım kaplamaların, yapısında $\% 100$ oranında çinko içeren kaplamalara kıyasla 8 kat daha yüksek korozyon dayanımına sahip olduğu sonucuna ulaşılmıştır. Bu nedenle asitli çinko nikel alaşım kaplamaların yüksek akım veriminden dolayı parçanın her bölgesini iyi kaplayabilme yeteneğine ve yüksek korozyon dayanımına sahip oldukları belirlenmiştir (Yılmaz, 2013). Bir başka çalışmada, parçadan beklenen özellikler ve kullanım yerine göre nikel, krom, çinko, kalay, bakır, soy metal kaplama ve NiCo, Ni-W vb. alaşım kaplama yöntemlerinden en uygun olanının seçimi gerçekleştirilmiştir. Çinkonun elektrokimyasal özelliği ve ekonomik olması çinko kaplamaların, çeliğin korozyona karşı korunmasındaki kullanımını yaygınlaştırmıştır (Uyanık, 2012). Çinko-alüminyum alaşımlarından üretilen döküm parçalarının yüzeyine yapılan elektrokimyasal kaplamaların, parça yüzeyine iyi yapışması için çeşitli yöntemler kullanılmaktadır. Ara katman olarak elektrolitik bakır kaplama bu amaçla sıç̧a tercih edilmektedir. Polat vd. (2013) yaptıkları çalışmada, ara katman uygulamalarında en sık kullanılan asidik ve siyanürsüz alkali bakır filmlerinin özelliklerini incelenmiş; çinko-alüminyum alaşımlarından üretilen döküm parçalarının üzerine bakır ara katmanı atıldıktan sonra farklı kaplamalar (krom, nikel, lak) uygulanarak elde edilen sekiz adet ürünün (kapı kolu) korozyon davranışını, ASTM B117 standartlarına uygun olarak test etmiştir. Fujita ve Mizuno (2007), otomobillerde çinko ve çinko alaşımı kaplı çelik sacların perforasyon korozyonuna etkisini ve hızlandırılmış korozyon test yöntemlerini incelemiştir. Bindirmeli panellerin çatlaklarında korozyonu etkileyen ana faktörün, kaplama tipinden çok çinko ve çinko alaşımlarının kaplama ağırlıkları olduğunu bildirmiştir. Nadir toprak metalleri (NTM) ilavesinin (ağırlıkça \%0,05-0,5 aralığında) sıcak daldırma galvanizli çeliğin yüzey morfolojisi ve korozyon direncine etkisinin incelendiğgi bir çalışmada, erimiş çinko galvanizleme banyosuna küçük miktarlarda NTM eklenmesinin korozyon direncini geliştirdiği belirlenmiştir (Amadeh vd., 2002). Ramanauskas vd. (1997) alkali banyolarda çökeltilen kromatsiz Zn, Zn-Co, Zn-Fe ve Zn-Ni kaplamalar için kristalografik doku ve lattis hücre parametrelerini belirleyerek, havalandırılmış klorür çözeltilerinde ve nötr tuz püskürtme testlerinde kaplamaların korozyon davranışlarında gözlenen farklılıkları ortaya koymuştur. Çinko matrisinde nikel veya kobalt varlığının Zn kaplama korozyon direncini arttırdığı, ancak demirin etkisinin bulunmadı $\breve{g}_{1}$ belirlenmiştir.

Günümüzde, toz boyaların yüksek mikronlarda üretilmesi hem maliyet açısından hem de montaj sırasında ekstra işçilik gereksiniminden dolayı zor bir kaplama sürecini gerektirmektedir. Bununla birlikte, çinko-lamelli kaplama, fosfat kaplama, çinko kaplama ve kataforez kaplama tek başına uygulandığında istenilen korozyon performansı elde edilememektedir. Kataforez kaplama ile çok kompleks parçalar kaplanabildiği için sanayide çok geniş bir kullanım alanı bulmuştur. Yukarıda belirtilen nedenlere ek olarak, 2010 yılından sonra otomotiv sektöründe kilit menteşe grupları, bağlantı elemanları ve akü bağlantı elemanları gibi parçalarda yüksek korozyon direnci, yüksek kimyasal dirençten dolayı yeni bir kaplama yönteminin geliştirilmesine ilişkin araştırmalar da bu çalışmanın gerçekleştirilmesine öncü olmuştur (Kılınç, 2019). $\mathrm{Bu}$ çalışmanın literatürde yer alan diğer çalışmalar farkı; en iyi yöntem olarak kataforez kaplamanın yüksek korozyon, yapışma, penetrasyon gibi özellikleriyle birlikte çinko alaşımlı kaplamanın kimyasal direnç, sürtünme katsayısı, ince ve homojen kaplama kalınlığı gibi özelliklerinin bir araya getirilmesidir.

\section{Materyal ve Metot}

Otomotiv sektöründe yaygın olarak kullanılan F899 ve F990 sicak-dövme döküm malzemelerin çinko ve kataforez kaplama süreçleri ile malzemelerin karakterizasyon yöntemleri bu bölümde açıklanmıştır. Çinko ve kataforez kaplama prosesleri Uzman Kataforez Yüzey Kaplama San. ve Tic. A.Ş. firmasında uygulanan daldırma yöntemli proseslerdir. Çinko kaplama prosesi genel olarak yă alma (alkali-asidik-ultrasonikelektirikli), nötürleme, durulama, çinko kaplama ve kurutma banyolarından oluşmaktadır. Kataforez kaplama prosesi genel olarak yağ alma (alkali), durulama, aktivasyon, fosfat, pasivasyon, deiyonize durulama, kataforez kaplama, ultrafitrasyon durulama banyolarından ve kürlenme firınından oluşmaktadır.

\subsection{Yüzey Temizliği ve Hazırlanması}

Kaplama öncesi yapılan yağ alma işlemi kumlama yapılacak olan parçaların üzerindeki yağların alınıp daha iyi kumlama işlemine olanak sağlanması için yapılmıştır. Mekanik bir temizleme yöntemi olan kumlama işlemi; metal yüzeyde kalabilecek tüm kimyasalların, metal çapaklarının ve daha öncesinde oluşabilecek pasların sökülerek, yüzeyin kaplamaya uygun bir hale getirilmesi için kullanılır. Numunelere alkali çinko, alkali çinko-demir, alkali çinko-nikel, asitli çinko ve asitli çinko-nikel kaplama öncesi yağ alma ve kumlama işlemi 
uygulanmıştır. $\mathrm{Bu}$ işlemlere ait teorik parametreler Tablo 1'de verilmiştir (Ekinoks Kimya Cleanox 1972 TDS, 2018; Uzman Kataforez Yüzey Kaplama San. Ve Tic. A.Ş., 2019).

Tablo 1. Yağ alma ve kumlama çalışma parametreleri

\begin{tabular}{l|l|c}
\hline İşlem & Parametre & Teorik \\
\hline \multirow{3}{*}{ Sicak yağ alma } & Süre $(\mathrm{dk})$. & $1-30$ \\
\cline { 2 - 3 } & Sicaklık $\left({ }^{\circ} \mathrm{C}\right)$ & $50-85$ \\
\cline { 2 - 3 } & $\begin{array}{l}\text { Konsantrasyon } \\
(\% \mathrm{ml})\end{array}$ & $3-10$ \\
\hline Kumlama & Süre $(\mathrm{dk})$. & $\geq 10$ \\
\hline
\end{tabular}

\section{2. Çinko ve Kataforez Kaplama Prosesleri}

Yağ alma ve kumlama işlemine tabi tutulan parçalara 12 -15 $\mu \mathrm{m}$ aralığında alkali çinko, alkali çinko-demir, alkali çinkonikel, asitli çinko ve asitli çinko-nikel kaplama işlemi yapılmıştır. Çinko ve alaşımları kaplanacak parçalar öncelikle parçaya özgü kanca kısımları hariç plastik kaplı özel askılara asılarak parça için oluşturulan reçeteye göre üretime alınmakta, sırasıyla belirlenen banyo sürelerine göre otomasyon sistemi yardımıyla banyolara daldırılarak kaplama işlemi gerçekleştirilmektedir. Çinko-esaslı kaplama işlemleri için kullanılacak parametrelerin teorik değerleri Tablo 2-3'de verilmiştir (Ekinoks Kimya Alukleen CV TDS, 2017; Ekinoks Kimya Cleanox E TDS, 2019; Eser Kimya ES/FE 36 TDS, 2017; Eser Kimya ES/F1 TDS, 2017; Eser Kimya ES/RKR TDS, 2018; Eser Kimya ES/RKR-NI TDS, 2018; Eser Kimya ES/ZN-NI Plus TDS, 2017; Uzman Kataforez Yüzey Kaplama San. Ve Tic. A.Ş., 2019).

Tablo 2. Çinko kaplama prosesi genel hatları için teorik çalışma parametreleri

\begin{tabular}{|c|c|c|}
\hline İşlem & Parametre & Teorik \\
\hline \multirow{4}{*}{$\begin{array}{l}\text { Elektrikli Yağ } \\
\text { Alma }\end{array}$} & Süre (dk.) & $1-20$ \\
\hline & Sicaklik $\left({ }^{\circ} \mathrm{C}\right)$ & $50-80$ \\
\hline & Konsantrasyon $(\% \mathrm{ml})$ & $\% 4-6$ \\
\hline & $\begin{array}{l}\text { Akım Yoğunluğu } \\
\left(\mathrm{A} / \mathrm{dm}^{2}\right)\end{array}$ & $3-5$ \\
\hline \multirow{3}{*}{$\begin{array}{l}\text { Ultrasonik } \\
\text { Yağ Alma }\end{array}$} & Süre (dk.) & $1-20$ \\
\hline & Sicaklık $\left({ }^{\circ} \mathrm{C}\right)$ & $50-80$ \\
\hline & Konsantrasyon $(\% \mathrm{ml})$ & $\% 4-6$ \\
\hline \multirow{2}{*}{$\begin{array}{l}\text { Asidik Yă̆ } \\
\text { Alma }\end{array}$} & Süre (dk.) & $5-15$ \\
\hline & Konsantrasyon $(\% \mathrm{ml})$ & $10-30$ \\
\hline \multirow{2}{*}{ Nötürleme } & Süre (dk.) & $10-30$ \\
\hline & $\mathrm{pH}$ & $4-6$ \\
\hline $\begin{array}{l}\text { Çeşitli Çinko } \\
\text { Kaplama } \\
\text { Prosesleri }\end{array}$ & Parametreler & - \\
\hline \multirow{2}{*}{ Nötürleme } & Süre (dk.) & $5-60$ \\
\hline & $\mathrm{pH}$ & $1-2$ \\
\hline Hava Üfleme & Süre (dk.) & Min. 1 \\
\hline \multirow{2}{*}{$\begin{array}{l}\text { Kurutma } \\
\text { Firını }\end{array}$} & Süre (dk.) & $3-15$ \\
\hline & Sicaklık $\left({ }^{\circ} \mathrm{C}\right)$ & $50-110$ \\
\hline
\end{tabular}

Tablo 3. Çinko kaplama yöntemlerine ait teorik çalışma parametreleri

\begin{tabular}{|c|c|c|}
\hline İşlem & Parametre & Teorik \\
\hline \multirow{5}{*}{$\begin{array}{l}\text { Alkali Çinko } \\
\text { Kaplama }\end{array}$} & Süre (dk.) & $\begin{array}{c}1 \mu \mathrm{m} \text { için } \min . \\
3 \mathrm{dk} \text {. }\end{array}$ \\
\hline & Sicaklık $\left({ }^{\circ} \mathrm{C}\right)$ & $20-40$ \\
\hline & Çinko (gr/L) & $8-15$ \\
\hline & $\operatorname{Kostik}(\mathrm{g} / \mathrm{L})$ & $110-150$ \\
\hline & $\operatorname{Ak} 1 m\left(\mathrm{~A} / \mathrm{dm}^{2}\right)$ & $1-5$ \\
\hline \multirow{6}{*}{$\begin{array}{l}\text { Alkali Çinko } \\
\text { Demir } \\
\text { Kaplama }\end{array}$} & Süre (dk.) & $\begin{array}{c}1 \mu \mathrm{m} \text { için min. } \\
3 \mathrm{dk} \text {. }\end{array}$ \\
\hline & Sicaklik $\left({ }^{\circ} \mathrm{C}\right)$ & $20-30$ \\
\hline & Çinko (gr/L) & $8-12$ \\
\hline & Demir (ppm) & $50-150$ \\
\hline & Kostik (gr/L) & $110-140$ \\
\hline & $\operatorname{Ak} 1 m\left(\mathrm{~A} / \mathrm{dm}^{2}\right)$ & $1-5$ \\
\hline \multirow{6}{*}{$\begin{array}{l}\text { Alkali Çinko- } \\
\text { Nikel } \\
\text { Kaplama }\end{array}$} & Süre (dk.) & $\begin{array}{c}1 \mu \mathrm{m} \text { için min. } \\
3 \mathrm{dk} \text {. }\end{array}$ \\
\hline & Sicaklık $\left({ }^{\circ} \mathrm{C}\right)$ & $20-30$ \\
\hline & Çinko (gr/L) & $5,5-6,2$ \\
\hline & Nikel (gr/L) & $0,7-2$ \\
\hline & Kostik (gr/L) & $110-140$ \\
\hline & $\operatorname{Ak} 1 \mathrm{~m}\left(\mathrm{~A} / \mathrm{dm}^{2}\right)$ & $1-3$ \\
\hline \multirow{7}{*}{$\begin{array}{l}\text { Asitli Çinko } \\
\text { Kaplama }\end{array}$} & Süre (dk.) & $\begin{array}{c}1 \mu \mathrm{m} \text { için min } \\
3 \mathrm{dk} .\end{array}$ \\
\hline & $\mathrm{pH}$ & $4,5-5,5$ \\
\hline & Sicaklık $\left({ }^{\circ} \mathrm{C}\right)$ & $18-32$ \\
\hline & Toplam Çinko (gr/L) & $30-35$ \\
\hline & Toplam Klorür (gr/L) & $130-170$ \\
\hline & $\begin{array}{l}\text { Amonyum Klorür } \\
(\mathrm{gr} / \mathrm{L})\end{array}$ & $150-200$ \\
\hline & $\operatorname{Ak} 1 m\left(\mathrm{~A} / \mathrm{dm}^{2}\right)$ & $4-6$ \\
\hline \multirow{8}{*}{$\begin{array}{l}\text { Asitli Çinko- } \\
\text { Nikel } \\
\text { Kaplama }\end{array}$} & Süre (dk.) & $\begin{array}{c}1 \mu \mathrm{m} \text { için } \min . \\
3 \mathrm{dk} \text {. }\end{array}$ \\
\hline & $\mathrm{pH}$ & $4,5-5,5$ \\
\hline & Sicaklık $\left({ }^{\circ} \mathrm{C}\right)$ & $18-32$ \\
\hline & Toplam Çinko (gr/L) & $30-35$ \\
\hline & Toplam Klorür (gr/L) & $130-170$ \\
\hline & $\begin{array}{l}\text { Amonyum Klorür } \\
(\mathrm{gr} / \mathrm{L})\end{array}$ & $150-200$ \\
\hline & Toplam Nikel (gr/L) & $1-5$ \\
\hline & $\operatorname{Ak} 1 m\left(\mathrm{~A} / \mathrm{dm}^{2}\right)$ & $4-6$ \\
\hline
\end{tabular}

Son aşamada, alkali çinko, alkali çinko-demir, alkali çinkonikel, asitli çinko ve asitli çinko-nikel kaplama işlemine tabi tutulan parçalar üzerine $20-25 \mu \mathrm{m}$ aralığında kataforez kaplama işlemi yapılmıştır. Kataforez kaplama prosesinde de çinko kaplama ile aynı daldırma yöntemi uygulanmaktadır. Kataforez kaplama işlemi gerçekleştirilen parçalar, kaplama sonrası boyanın kürlenmesi için belirli süre fırında kürlendirilmektedir. Ayrıca, çinko kaplamada kullanılan özel plastik kaplı askılar yerine metal askılar üzerine parçalar takılmaktadır. Çinko kaplama prosesinde metal askı kullanıldığı takdirde askının yüzeyinin de kaplanmasına bağlı olarak maliyet artmaktadır. Kataforez kaplama işleminde ise bu durum söz konusu değildir. 
Kataforez kaplama işlemleri için kullanılacak parametrelerin teorik değerleri Tablo 4'te verilmiştir (Chemetall Gardobond AP9809 TDS, 2017; Chemetall Gardobond 24T TDS, 2018; Chemetall Gardolene V 6513 TDS, 2017; Ppg CP458A TDS, 2017; Ppg Powercon P6200 TDS, 2018).

Tablo 4. Kataforez kaplama çalışmasına ait teorik parametreler

\begin{tabular}{|c|c|c|c|}
\hline İşlem & \multicolumn{2}{|c|}{ Parametre } & Teorik \\
\hline \multirow{3}{*}{$\begin{array}{l}\text { Sicak Yağ } \\
\text { Alma }\end{array}$} & \multicolumn{2}{|l|}{ Süre (dk.) } & $5-10$ \\
\hline & \multicolumn{2}{|c|}{ Sicaklık $\left({ }^{\circ} \mathrm{C}\right)$} & $50-85$ \\
\hline & \multicolumn{2}{|c|}{ Konsantrasyon $(\% \mathrm{ml})$} & $3-10$ \\
\hline \multirow{2}{*}{ Aktivasyon } & \multicolumn{2}{|c|}{ Süre (dk.) } & $30-60$ \\
\hline & \multicolumn{2}{|l|}{$\mathrm{pH}$} & $8,5-10$ \\
\hline \multirow{10}{*}{$\begin{array}{l}\text { Fosfat } \\
\text { Kaplama }\end{array}$} & \multicolumn{2}{|l|}{ Süre (dk.) } & $2-5$ \\
\hline & \multicolumn{2}{|c|}{ Toplam Asit $(\% \mathrm{ml})$} & $17-25$ \\
\hline & \multicolumn{2}{|c|}{ Serbest Asit $(\% \mathrm{ml})$} & $0,6-1,1$ \\
\hline & \multicolumn{2}{|c|}{ Hizlandırıcı (\%ml) } & $1,5-3$ \\
\hline & \multicolumn{2}{|c|}{ Toplam Flor (ppm) } & $550-850$ \\
\hline & \multicolumn{2}{|c|}{ Serbest Flor (ppm) } & $50-150$ \\
\hline & \multicolumn{2}{|c|}{ Nikel Oranı (gr/L) } & $0,6-1,1$ \\
\hline & \multicolumn{2}{|c|}{ Çinko Oranı (gr/L) } & $0,6-1,2$ \\
\hline & \multicolumn{2}{|c|}{ Mangan Oranı (gr/L) } & $0,2-0,5$ \\
\hline & \multicolumn{2}{|c|}{ Demir Oranı (ppm) } & Max. 7 \\
\hline \multirow{3}{*}{ Pasivasyon } & \multicolumn{2}{|l|}{ Süre (dk.) } & Min. 15 \\
\hline & \multicolumn{2}{|c|}{ Titrasyon Noktası $(\% \mathrm{ml})$} & $1,7-6,9$ \\
\hline & \multicolumn{2}{|c|}{ İletkenlik $(\mu \mathrm{S})$} & Max. 900 \\
\hline \multirow{10}{*}{ Kataforez } & \multicolumn{2}{|c|}{ Süre (dk.) } & $3-5$ \\
\hline & \multicolumn{2}{|c|}{ Katı Miktarı (\%) } & $14-20$ \\
\hline & \multicolumn{2}{|c|}{ Kül Miktarı (\%) } & $1,2-2,5$ \\
\hline & \multicolumn{2}{|l|}{$\mathrm{P} / \mathrm{L}$ Oranı } & $0,11-0,16$ \\
\hline & \multicolumn{2}{|c|}{ Sicaklık $\left({ }^{\circ} \mathrm{C}\right)$} & $29-35$ \\
\hline & \multirow{2}{*}{$\mathrm{pH}$} & Kataforez & $5,6-6,1$ \\
\hline & & DI Su Tankı & $5,5-7,5$ \\
\hline & & Kataforez $(\mu \mathrm{S})$ & $1000-2000$ \\
\hline & İletkenlik & Anolit Tankı $(\mu \mathrm{S})$ & $4000-6000$ \\
\hline & & DI Su Tankı $(\mu \mathrm{S})$ & $10-250$ \\
\hline & Süre (dk.) & & $1-10$ \\
\hline Ultrafiltrat & İletkenlik & $\mu \mathrm{S})$ & $400-1200$ \\
\hline & $\mathrm{pH}$ & & $5,6-6$ \\
\hline Pişirme & Süre (dk.) & & Min. 15 \\
\hline Fırını & Sicaklık ( ${ }^{\circ}$ & & Min. 155 \\
\hline
\end{tabular}

\subsection{Kaplama Karakterizasyonu}

Numunelere uygulanan kaplama işlemlerinin kalitesinin ve korozyon direncinin belirlenmesi amacıyla çeşitli karakterizasyon işlemleri gerçekleştirilmiştir. $\mathrm{Bu}$ amaçla mürekkep testi, hogobom testi, şok testi gibi testlerin sonucu görsel açıdan değerlendirilerek kaplamanın uygunluğu hakkında yorum yapılmıştır. Ayrıca, X-ışını kırınım laminografi (Helmut Fischer XDL-B XYmZ), SEM (Hitachi TM - 1000), pull-off adhezyon (DeFelsko), su direnci (Nüve BM 402), tuz sisi (Vötsch SC1000), taş çarpma (Gravelometer), çevrimsel korozyon (Ascott CC1000IP) ve scab korozyon (Angelantoni e-ISSN: 2148-2683
DCTC 1200P) cihazları kullanılarak gerçekleştirilen ölçümlerin sonuçları incelenmiştir.

\section{Araştırma Sonuçları ve Tartışma}

Kaplama öncesi yüzey temizliği, alkali çinko, alkali çinkodemir, alkali çinko-nikel, asitli çinko ve asitli çinko-nikel kaplama ve son olarak kataforez kaplama uygulanan numunelerin test sonuçları bu bölümde ayrıntılı olarak incelenmiştir.

\subsection{Mürekkep testi}

Tablo 5'te sunulan, çeşitli çinko kaplama süreçleri öncesi uygulanan yağ alma işlemine ait ölçülen değerlerin teorik değer aralıklarında olduğu görülmektedir. Alkali çinko, alkali çinkodemir, alkali çinko-nikel, asitli çinko ve asitli çinko-nikel kaplanacak tüm numunelere kaplama öncesi yapılacak yağ alma işleminin uygunluğu mürekkep testi ile belirlenmiştir. Tüm test sonuçları Şekil 1'de gösterilmiştir. Uygulanan yağ alma işleminin kabul edilebilmesi için parça yüzeyine çizilen mürekkebin test sonunda da düz bir hat şeklinde kalması, yă alma işleminin etkin olarak yapıldığını göstermektedir. Buna göre, her iki döküm malzemeye ugulanan $5 \mathrm{dk}$ ve $15 \mathrm{dk}$ yă alma işlemlerinin yetersiz kaldığı, ancak 20 dakika yağ alma işlemi yapılan malzemelerin testi geçtiği (Şekil 1.c ve f) belirlenmiştir (International Standard ISO 8296, 2003).

\section{Tablo 5. Yağ alma süreci ölçülen çalışma parametreleri}

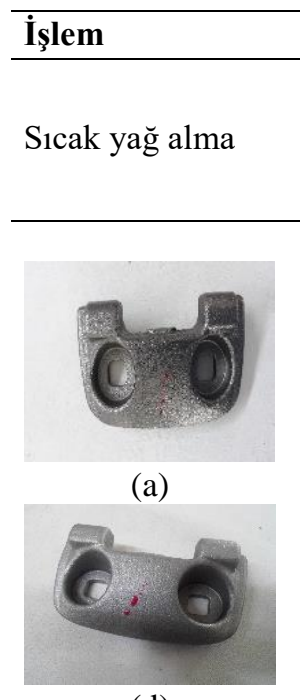

(d)

\begin{tabular}{|l}
\hline Parametre \\
\hline Süre $(\mathrm{dk})$. \\
\hline Sicaklık $\left({ }^{\circ} \mathrm{C}\right)$ \\
\hline Konsantrasyon $(\%$ \\
\hline
\end{tabular}

(b)

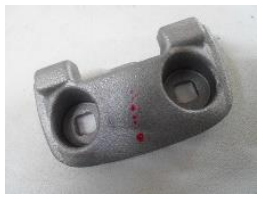

(e)

\begin{tabular}{c|c} 
& Ölçülen \\
\hline & 5,15 ve 20 \\
\hline 1$)$ & 53
\end{tabular}

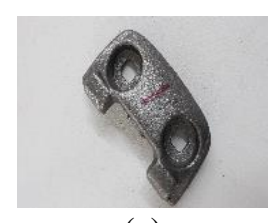

(c)

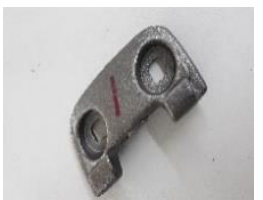

(f)
Şekil 1. Mürekkep testi sonuçlart: F899 için (a) $5 \mathrm{dk}$, (b) $15 \mathrm{dk}$ ve (c) 20 dk yağ alma işlemi, F990 için (d) 5 dk, (e) 15 dkve (f) 20 dk yağ alma işlemi

\subsection{Hogabom Testi}

Yüzey temizliğinin sağlanması amacıyla gerçekleştirilen kumlama işleminin minimum $10 \mathrm{dk}$. boyunca sürdürülmesi gerektiği Tablo 1'de belirtilmiştir. Alkali çinko, alkali çinkodemir, alkali çinko-nikel, asitli çinko ve asitli çinko-nikel kaplanacak tüm numunelere kaplama öncesi yapılacak kumlama işleminin uygunluğu hogabom testi ile incelenmiştir. Tüm test sonuçları Şekil 2'de gösterilmiştir. Uygulanan kumlama işleminin kabul edilebilmesi için hazırlanan çözeltideki bakırın metal parça yüzeyine iyi ve homojen bir şekilde yapışması gerekmektedir. Buna göre, 5 dakikalık kumlama işleminde homojen bir kaplama elde edilemezken, 10 dakika kumlama 
işlemi yapılan malzemelerin yüzeyinin pürüzsüz olmasına bağlı olarak bakır iyonlarının metal yüzeyine uniform biçimde yapıştı̆̆ı belirlenmiştir (Şekil 2.b ve d) (NOF Metal Coatings Group, 2017).

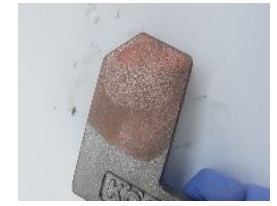

(a)

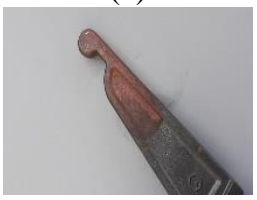

(c)

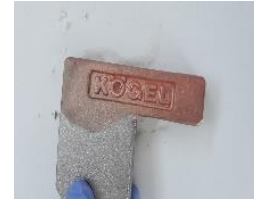

(b)

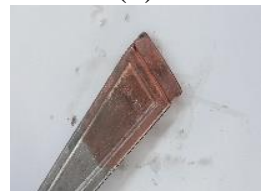

(d)
Şekil 2. Hogabom testi sonuçları: F899 için (a) $5 \mathrm{dk}$ ve (b) $10 \mathrm{dk}$ kumlama işlemi, F990 için (c) 5 dk ve (d) 10 dk kumlama işlemi

\subsection{Sok Testi}

12-15 $\mu \mathrm{m}$ alkali çinko, alkali çinko-demir, alkali çinkonikel, asitli çinko ve asitli çinko-nikel kaplanacak numuneler için kaplama öncesi yapılacak ultrasonik yă̆ alma işleminin uygunluğu şok testi ile ölçülmüştür. Tüm test sonuçları Şekil 3 'te gösterilmiştir. Uygulanan ultrasonik yağ alma işleminin kabul edilebilmesi için, parça yüzeyinde yapışmadan kaynaklı kabarma ve atma olmaması gerekmektedir. Buna göre, ultrasonik yağ alma işlemi uygulanmayan numunelerin testi geçemediği, ancak $10 \mathrm{dk}$.'llk ultrasonik yağ alma işlemi uygulanan numunelerin şok testinde uygun sonuçlar elde edildiği belirlenmiştir (Adhesion Test 50765, 1990).

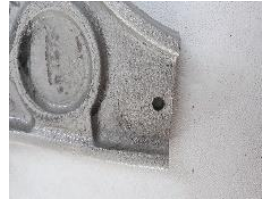

(a)

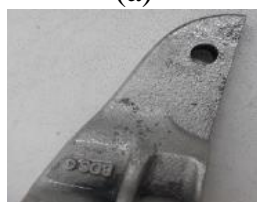

(d)

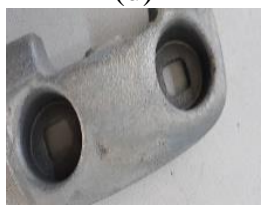

(g)

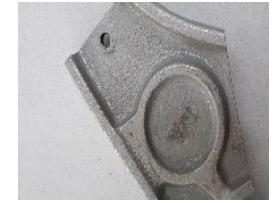

(b)

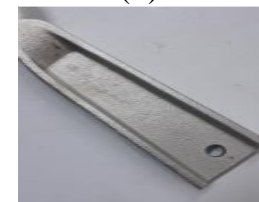

(e)

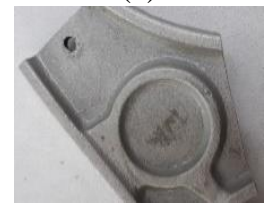

(h)

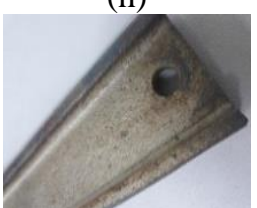

(j)

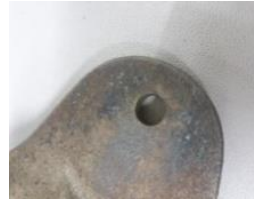

(c)

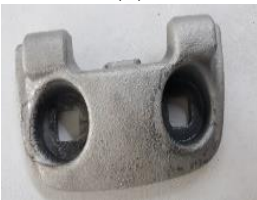

(f)

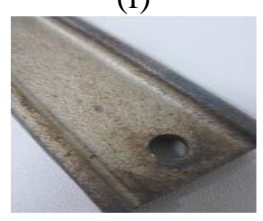

(i)
Sekil 3. Sok testi sonuçları: alkali çinko için (a) F899 ve (f) F990, alkali çinko-demir için (b) F899 ve (g) F990, alkali çinkonikel için (c) F899 ve (h) F990, asitli çinko için (d) F899 ve (i) F990, asitli çinko-nikel için (e) F899 ve (j) F990 (Ultrasonik yağ alma $=10 \mathrm{dk}$.)

\section{4. Çinko ve Kataforez Kaplama Proseslerine Ait Ölçülen Banyo Parametreleri}

Temizleme işleminden alınan parçalar üzerine uygulanan 12 $-15 \mu \mathrm{m}$ aralığında çinko ve $20-25 \mu \mathrm{m}$ aralığında kataforez kaplama işlemlerine ait ölçülen banyo parametreleri Tablo 68'de verilmiştir. Ölçülen parametrelerin Tablo 6-8'de verilen teorik değer aralıklarında olduğu açıkça görülmektedir.

Tablo 6. Çinko kaplama prosesi genel hatları için ölçülen çalışma parametreleri

\begin{tabular}{|c|c|c|}
\hline İşlem & Parametre & Ölçülen \\
\hline \multirow{4}{*}{$\begin{array}{l}\text { Elektrikli Yağ } \\
\text { Alma }\end{array}$} & Süre (dk.) & 10 \\
\hline & Sicaklık $\left({ }^{\circ} \mathrm{C}\right)$ & 53 \\
\hline & Konsantrasyon $(\% \mathrm{ml})$ & 5 \\
\hline & $\begin{array}{l}\text { Akım Yoğunluğu } \\
\left(\mathrm{A} / \mathrm{dm}^{2}\right)\end{array}$ & 4,5 \\
\hline \multirow{3}{*}{$\begin{array}{l}\text { Ultrasonik Yağ } \\
\text { Alma }\end{array}$} & Süre (dk.) & 10 \\
\hline & Sicaklık $\left({ }^{\circ} \mathrm{C}\right)$ & 55 \\
\hline & Konsantrasyon $(\% \mathrm{ml})$ & 4 \\
\hline \multirow{2}{*}{ Asidik Yağ Alma } & Süre (dk.) & 8 \\
\hline & Konsantrasyon $(\% \mathrm{ml})$ & 18 \\
\hline \multirow{2}{*}{ Nötürleme } & Süre (dk.) & 30 \\
\hline & $\mathrm{pH}$ & 4,7 \\
\hline $\begin{array}{l}\text { Çeşitli Çinko } \\
\text { Kaplama } \\
\text { Prosesleri }\end{array}$ & Parametreler & - \\
\hline \multirow{2}{*}{ Nötürleme } & Süre (dk.) & 30 \\
\hline & $\mathrm{pH}$ & 2 \\
\hline Hava Üfleme & Süre (dk.) & 2 \\
\hline \multirow{2}{*}{ Kurutma Firını } & Süre (dk.) & 10 \\
\hline & Sicaklık $\left({ }^{\circ} \mathrm{C}\right)$ & 98 \\
\hline
\end{tabular}

\subsection{X-Işını Kırınım Laminografi Cihazında Çinko Kaplama Kalınlık Ölçümü}

12-15 $\mu \mathrm{m}$ alkali çinko, alkali çinko-demir, alkali çinkonikel, asitli çinko ve asitli çinko-nikel kaplanacak tüm numunelerin kaplama kalınlığı X-1şını kırınım laminografi cihazı ile ölçülmüştür. Tüm test sonuçları Şekil 4'te gösterilmiştir. Uygulanan kaplama işleminin kabul edilebilmesi için kaplama kalınlığı 12-15 $\mu \mathrm{m}$ arasında çıkmalıdır. Tablo 9'a göre, tüm parçaların ölçülen kaplama kalınlıkları istenilen aralıkta çıkmıştır (International Standard ISO 3497, 2001).

\subsection{SEM Analizi ile Fosfat Kaplama Görünümü ve Krsital Büyüklüğü Ölçümü}

12-15 $\mu \mathrm{m}$ alkali çinko, alkali çinko-demir, alkali çinkonikel, asitli çinko ve asitli çinko-nikel kaplanacak numuneler üzerine kaplanan fosfat kaplamaların örtücülüğü ve kristal büyüklükleri SEM cihazı ile incelenmiştir. SEM analizi görüntüleri Şekil 5 'te ve ölçülen kristal büyüklükleri Tablo 10'da verilmiştir. Fosfat kaplamanın kabul edilebilmesi için fosfatın tüm yüzeyi örtmesi ve fosfat kristallerinin 3-6 $\mu \mathrm{m}$ büyüklüğünde olması gerekmektedir. SEM görüntülerine göre, fosfat kaplamaların tüm yüzeyi örtüğ̈̈ ve fosfat kristallerinin 3,11-5,60 $\mu \mathrm{m}$ büyüklüğünde olduğu belirlenmiştir. Buna göre, fosfat kaplama işleminin tüm numunelere başarılı bir şekilde 
uygulandığı görülmüştür (Volvo car corporation test standart VCS 5740,1049, 2011).

Tablo 7. Çinko kaplama yöntemlerine ait ölçülen çalışma parametreleri

\begin{tabular}{|c|c|c|}
\hline İşlem & Parametre & Ölçülen \\
\hline \multirow{5}{*}{$\begin{array}{l}\text { Alkali Çinko } \\
\text { Kaplama }\end{array}$} & Süre (dk.) & 42 \\
\hline & Sicaklık $\left({ }^{\circ} \mathrm{C}\right)$ & 23 \\
\hline & Çinko (gr/L) & 12 \\
\hline & $\operatorname{Kostik}(\mathrm{g} / \mathrm{L})$ & 132 \\
\hline & $\operatorname{Akım}\left(\mathrm{A} / \mathrm{dm}^{2}\right)$ & 3,5 \\
\hline \multirow{6}{*}{$\begin{array}{l}\text { Alkali Çinko } \\
\text { Demir Kaplama }\end{array}$} & Süre (dk.) & 45 \\
\hline & Sicaklık $\left({ }^{\circ} \mathrm{C}\right)$ & 28 \\
\hline & Çinko (gr/L) & 9 \\
\hline & Demir (ppm) & 90 \\
\hline & Kostik (gr/L) & 130 \\
\hline & $\operatorname{Akım}\left(\mathrm{A} / \mathrm{dm}^{2}\right)$ & 4 \\
\hline \multirow{6}{*}{$\begin{array}{l}\text { Alkali Çinko- } \\
\text { Nikel Kaplama }\end{array}$} & Süre (dk.) & 45 \\
\hline & Sicaklık $\left({ }^{\circ} \mathrm{C}\right)$ & 29 \\
\hline & Çinko (gr/L) & 6 \\
\hline & Nikel (gr/L) & 1,9 \\
\hline & Kostik (gr/L) & 138 \\
\hline & $\operatorname{Akım}\left(\mathrm{A} / \mathrm{dm}^{2}\right)$ & 2,5 \\
\hline \multirow{7}{*}{$\begin{array}{l}\text { Asitli Çinko } \\
\text { Kaplama }\end{array}$} & Süre (dk.) & 45 \\
\hline & $\mathrm{pH}$ & 5 \\
\hline & Sicaklık $\left({ }^{\circ} \mathrm{C}\right)$ & 30 \\
\hline & Toplam Çinko (gr/L) & 32 \\
\hline & Toplam Klorür (gr/L) & 150 \\
\hline & Amonyum Klorür (gr/L) & 190 \\
\hline & $\operatorname{Akım}\left(\mathrm{A} / \mathrm{dm}^{2}\right)$ & 5 \\
\hline \multirow{8}{*}{$\begin{array}{l}\text { Asitli Çinko- } \\
\text { Nikel Kaplama }\end{array}$} & Süre (dk.) & 45 \\
\hline & $\mathrm{pH}$ & 5,2 \\
\hline & Sicaklik $\left({ }^{\circ} \mathrm{C}\right)$ & 31 \\
\hline & Toplam Çinko (gr/L) & 31 \\
\hline & Toplam Klorür (gr/L) & 155 \\
\hline & Amonyum Klorür (gr/L) & 165 \\
\hline & Toplam Nikel (gr/L) & 4 \\
\hline & $\operatorname{Akım}\left(\mathrm{A} / \mathrm{dm}^{2}\right)$ & 5 \\
\hline
\end{tabular}

Tablo 8. Kataforez kaplama çalışmasına ait ölçülen parametreler

\begin{tabular}{|c|c|c|c|}
\hline İşlem & \multicolumn{2}{|c|}{ Parametre } & Ölçülen \\
\hline \multirow{3}{*}{$\begin{array}{l}\text { Sicak Yağ } \\
\text { Alma }\end{array}$} & \multicolumn{2}{|l|}{ Süre (dk.) } & 7 \\
\hline & \multicolumn{2}{|c|}{ Sicaklık $\left({ }^{\circ} \mathrm{C}\right)$} & 52 \\
\hline & \multicolumn{2}{|c|}{ Konsantrasyon (\% ml) } & 4 \\
\hline \multirow{2}{*}{ Aktivasyon } & \multicolumn{2}{|l|}{ Süre (dk.) } & 45 \\
\hline & \multicolumn{2}{|l|}{$\mathrm{pH}$} & 9,5 \\
\hline \multirow{10}{*}{$\begin{array}{l}\text { Fosfat } \\
\text { Kaplama }\end{array}$} & \multicolumn{2}{|l|}{ Süre (dk.) } & 3 \\
\hline & \multicolumn{2}{|c|}{ Toplam Asit (\%ml) } & 23 \\
\hline & \multicolumn{2}{|c|}{ Serbest Asit (\%ml) } & 1 \\
\hline & \multicolumn{2}{|c|}{ Hizlandırıcı (\%ml) } & 2,7 \\
\hline & \multicolumn{2}{|c|}{ Toplam Flor (ppm) } & 770 \\
\hline & \multicolumn{2}{|c|}{ Serbest Flor (ppm) } & 85 \\
\hline & \multicolumn{2}{|c|}{ Nikel Oranı (gr/L) } & 0,82 \\
\hline & \multicolumn{2}{|c|}{ Çinko Oranı (gr/L) } & 1,1 \\
\hline & \multicolumn{2}{|c|}{ Mangan Oranı (gr/L) } & $0,42 \mathrm{~L}$ \\
\hline & \multicolumn{2}{|c|}{ Demir Oranı (ppm) } & 0 \\
\hline \multirow{3}{*}{ Pasivasyon } & \multicolumn{2}{|l|}{ Süre (dk.) } & 30 \\
\hline & \multicolumn{2}{|c|}{ Titrasyon Noktası $(\% \mathrm{ml})$} & 3,5 \\
\hline & \multicolumn{2}{|c|}{ İletkenlik $(\mu \mathrm{S})$} & 700 \\
\hline \multirow{10}{*}{ Kataforez } & \multicolumn{2}{|l|}{ Süre (dk.) } & 3,05 \\
\hline & \multicolumn{2}{|c|}{ Kat1 Miktar1 (\%) } & 16 \\
\hline & \multicolumn{2}{|c|}{ Kül Miktarı (\%) } & 1,7 \\
\hline & \multicolumn{2}{|l|}{$\mathrm{P} / \mathrm{L}$ Oranı } & 0,14 \\
\hline & \multicolumn{2}{|c|}{ Sicaklık $\left({ }^{\circ} \mathrm{C}\right)$} & 32 \\
\hline & \multirow{2}{*}{$\mathrm{pH}$} & Kataforez & 6 \\
\hline & & DI Su Tankı & 6,5 \\
\hline & & Kataforez $(\mu \mathrm{S})$ & 1300 \\
\hline & İletkenlik & Anolit Tankı $(\mu \mathrm{S})$ & 700 \\
\hline & & DI Su Tankı $(\mu \mathrm{S})$ & 650 \\
\hline & Süre (dk.) & & 1 \\
\hline Ultrafiltrat & İletkenlik & $\mu \mathrm{S})$ & 1000 \\
\hline & $\mathrm{pH}$ & & 5,8 \\
\hline Pişirme & Süre (dk.) & & 62 \\
\hline Firını & Sicaklik ( ${ }^{\circ}$ & & 200 \\
\hline
\end{tabular}

Tablo 9. X-ışını kırınım laminografi cihazı kaplama kalınlık ölçüm sonuçları (istenilen kaplama kalınlığı: 12-15 ㅆm)

\begin{tabular}{l|c|c|c|c|c}
\hline \multirow{2}{*}{$\begin{array}{l}\text { Döküm } \\
\text { Kodu }\end{array}$} & \multicolumn{4}{|c}{ Kaplama Çeşidi } \\
\cline { 2 - 6 } & $\begin{array}{c}\text { Alkali çinko }+ \\
\text { fosfat }\end{array}$ & $\begin{array}{c}\text { Alkali çinko- } \\
\text { demir + fosfat }\end{array}$ & $\begin{array}{c}\text { Alkali çinko-nikel } \\
+ \text { fosfat }\end{array}$ & $\begin{array}{c}\text { Asitli çinko }+ \\
\text { fosfat }\end{array}$ & $\begin{array}{c}\text { Asitli çinko-nikel } \\
+ \text { fosfat }\end{array}$ \\
\hline F899 & $12,53 \mu \mathrm{m} /$ Uygun & $14,23 \mu \mathrm{m} /$ Uygun & $14,89 \mu \mathrm{m} /$ Uygun & $14,17 \mu \mathrm{m} /$ Uygun & $14,11 \mu \mathrm{m} /$ Uygun \\
\hline F990 & $12,27 \mu \mathrm{m} /$ Uygun & $12,53 \mu \mathrm{m} /$ Uygun & $12,10 \mu \mathrm{m} /$ Uygun & $12,09 \mu \mathrm{m} /$ Uygun & $12,71 \mu \mathrm{m} /$ Uygun \\
\hline
\end{tabular}




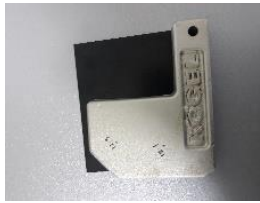

(a)

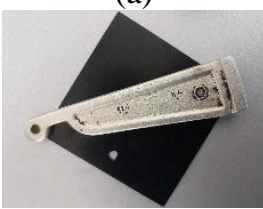

(f)

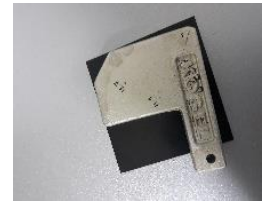

(b)

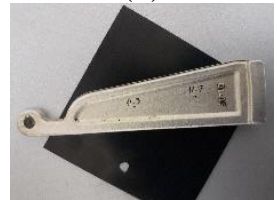

(g)

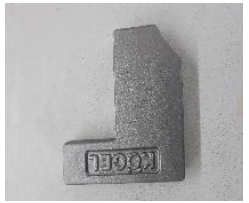

(c)

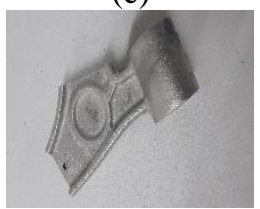

(h)

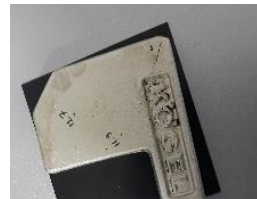

(d)

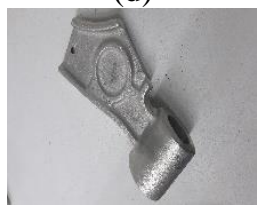

(i)

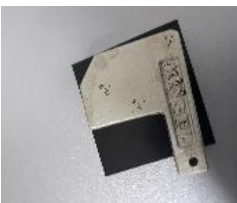

(e)

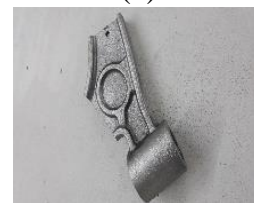

(j)

Şekil 4. X-ışını kırınım laminografi cihazında kaplama kalınlık sonuçları: alkali çinko için (a) F899 ve (f) F990, alkali çinko-demir için (b) F899 ve (g) F990, alkali çinko-nikel için (c) F899 ve (h) F990, asitli çinko için (d) F899 ve (i) F990, asitli çinko-nikel için (e) F899 ve (j) F990

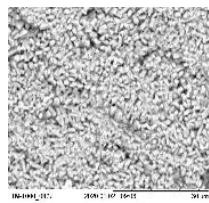

(a)

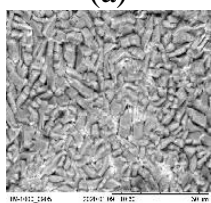

(f)

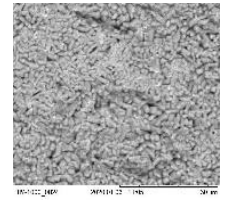

(b)

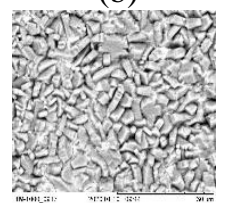

(g)

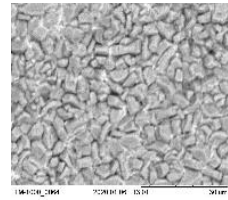

(c)

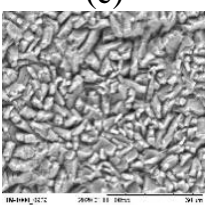

(h)

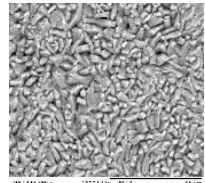

(d)

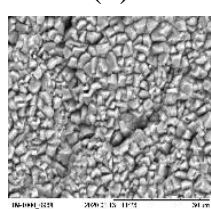

(i)

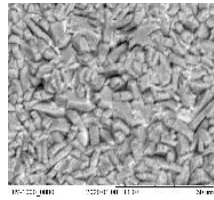

(e)

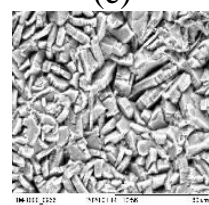

(j)

Şekil 5. Sem cihazı fosfat kristali gürünümü sonuçlarl: alkali çinko için (a) F899 ve (f) F990, alkali çinko-demir için (b) F899 ve (g) F990, alkali çinko-nikel için (c) F899 ve (h) F990, asitli çinko için (d) F899 ve (i) F990, asitli çinko-nikel için (e) F899 ve (j) F990

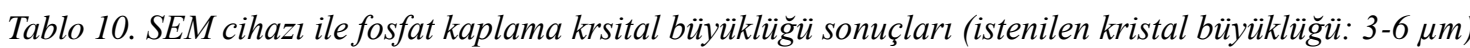

\begin{tabular}{l|c|c|c|c|c}
\hline \multirow{2}{*}{$\begin{array}{l}\text { Döküm } \\
\text { Kodu }\end{array}$} & \multicolumn{5}{|c}{ Kaplama Çeşidi } \\
\cline { 2 - 6 } & $\begin{array}{c}\text { Alkali çinko }+ \\
\text { fosfat }\end{array}$ & $\begin{array}{c}\text { Alkali çinko- } \\
\text { demir + fosfat }\end{array}$ & $\begin{array}{c}\text { Alkali çinko- } \\
\text { nikel + fosfat }\end{array}$ & $\begin{array}{c}\text { Asitli çinko }+ \\
\text { fosfat }\end{array}$ & $\begin{array}{c}\text { Asitli çinko-nikel } \\
+ \text { fosfat }\end{array}$ \\
\hline F899 & $3,38 \mu \mathrm{m} /$ Uygun & $3,27 \mu \mathrm{m} /$ Uygun & $3,89 \mu \mathrm{m} /$ Uygun & $5,12 \mu \mathrm{m} /$ Uygun & $5,60 \mu \mathrm{m} /$ Uygun \\
\hline F990 & $3,11 \mu \mathrm{m} /$ Uygun & $4,96 \mu \mathrm{m} /$ Uygun & $4,29 \mu \mathrm{m} /$ Uygun & $3,55 \mu \mathrm{m} /$ Uygun & $5,33 \mu \mathrm{m} /$ Uygun \\
\hline
\end{tabular}

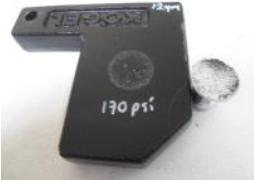

(a)

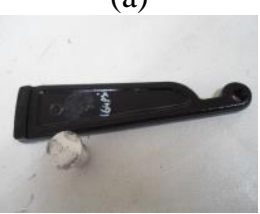

(f)

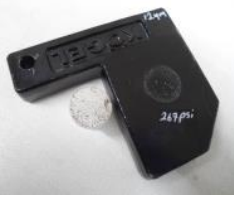

(b)

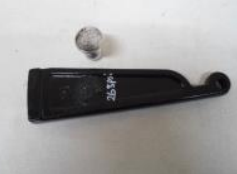

(g)

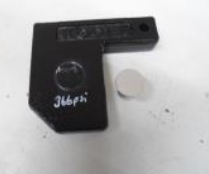

(c)

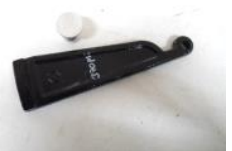

(h)

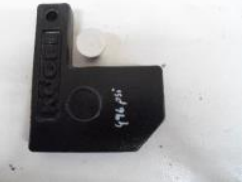

(d)

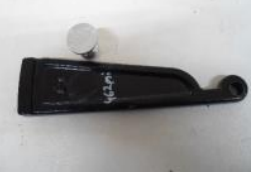

(i)

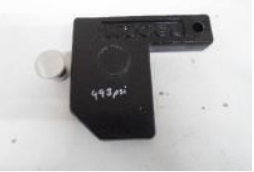

(e)

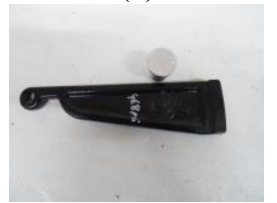

(j)

Şekil 6. Pull-Off adhezyon testi sonuçlart: alkali çinko için (a) F899 ve (f) F990, alkali çinko-demir için (b) F899 ve (g) F990, alkali çinko-nikel için (c) F899 ve (h) F990, asitli çinko için (d) F899 ve (i) F990, asitli çinko-nikel için (e) F899 ve (j) F990 


\subsection{Pull-Off Adhezyon Testi}

$\mathrm{Bu}$ işlem, organik kaplamaların yüzeylerinin yüzeye yapışma mukavemetlerini belirlemede kullanılan test yöntemidir. 12-15 $\mu \mathrm{m}$ alkali çinko, alkali çinko-demir, alkali çinko-nikel, asitli çinko ve asitli çinko-nikel üzerine uygulanan 20-25 $\mu \mathrm{m}$ kataforez kaplamaların çinko kaplamaya tutunumu pull-off adhezyon testi ile incelenmiştir (Şekil 6). Kataforez kaplamaların çinko kaplamaya tutunumun kabul edilebilmesi için tutunum değerinin 100 psi'nin altında olmaması gerekmektedir. Pull-off adhezyon testine göre, tutunma değerlerinin 164-496 psi arasında olması tutunmanın başarılı bir şekilde gerçekleştirildiğini göstermiştir (Tablo 11) (ASTM D4541 Standart test method, 2017).

\subsection{Su Direnci Testi}

12-15 $\mu \mathrm{m}$ alkali çinko, alkali çinko-demir, alkali çinkonikel, asitli çinko ve asitli çinko-nikel üzerine 20-25 $\mu \mathrm{m}$ kataforez kaplandıktan sonra Fiat'ın 50470 numaralı şartnamesine göre su direnci testi yapılmıştır (Şekil 7). Su direnci testine göre, kaplamaların Ad0, Ad1 ve Ad2 olmak üzere farklı yapışma direnci değerlerine sahip olduğu belirlenmiştir (Tablo 12). Uygulanan kaplamanın kabul edilebilmesi için yapışma direnci testi sonucunun Ad0 ve Ad1 olması ve kaplamanın renginde değişim gözlenmemesi gerekmektedir. Buna göre, alkali çinko + kataforez ve alkali çinko-demir + kataforez kaplanan F990 sıcak-dövme döküm numunesi hariç diğer tüm numuneler testi geçmiştir (Fiat Auto Normazione Material Standart 50470, 2005).

Tablo 11. Pull-off adhezyon ölçüm sonuçları (istenilen tutunum > 100 psi)

\begin{tabular}{l|c|c|c|c|c}
\hline \multirow{2}{*}{$\begin{array}{c}\text { Döküm } \\
\text { Kodu }\end{array}$} & \multicolumn{5}{|c}{ Kaplama Çeşidi } \\
\cline { 2 - 6 } & $\begin{array}{c}\text { Alkali çinko }+ \\
\text { kataforez }\end{array}$ & $\begin{array}{c}\text { Alkali çinko- } \\
\text { demir + kataforez }\end{array}$ & $\begin{array}{c}\text { Alkali çinko- } \\
\text { nikel + kataforez }\end{array}$ & $\begin{array}{c}\text { Asitli çinko }+ \\
\text { kataforez }\end{array}$ & $\begin{array}{c}\text { Asitli çinko-nikel } \\
+ \text { kataforez }\end{array}$ \\
\hline F899 & $170 \mathrm{psi} /$ Uygun & $267 \mathrm{psi} /$ Uygun & $366 \mathrm{psi} /$ Uygun & $496 \mathrm{psi} /$ Uygun & $493 \mathrm{psi} /$ Uygun \\
\hline F990 & $164 \mathrm{psi} /$ Uygun & $263 \mathrm{psi} /$ Uygun & $370 \mathrm{psi} /$ Uygun & $462 \mathrm{psi} /$ Uygun & $468 \mathrm{psi} /$ Uygun \\
\hline
\end{tabular}

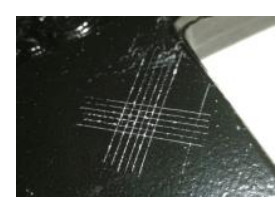

(a)

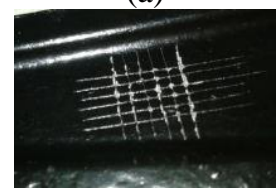

(f)

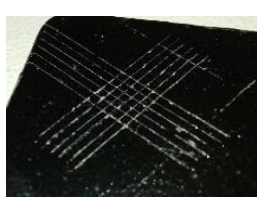

(b)

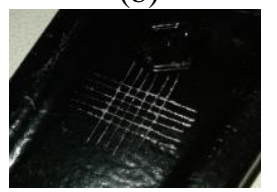

(g)

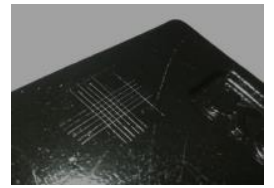

(c)

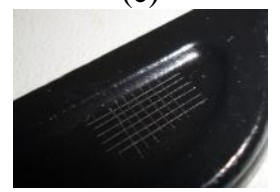

(h)

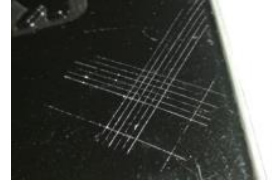

(d)

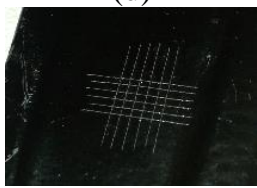

(i)

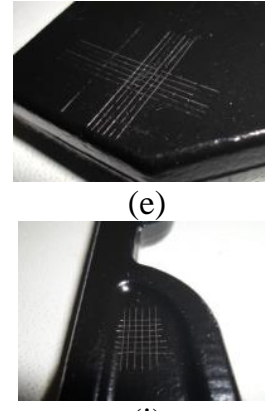

(j)

Şekil 7. Su direnci testi sonuçlart: alkali çinko için (a) F899 ve (f) F990, alkali çinko-demir için (b) F899 ve (g) F990, alkali çinkonikel için (c) F899 ve (h) F990, asitli çinko için (d) F899 ve (i) F990, asitli çinko-nikel için (e) F899 ve (j) F990

Tablo 12. Su direnci ölçüm sonuçları

\begin{tabular}{l|c|c|c|c|c}
\hline \multirow{2}{*}{$\begin{array}{c}\text { Döküm } \\
\text { Kodu }\end{array}$} & \multicolumn{5}{|c}{ Kaplama Çeşidi } \\
\cline { 2 - 6 } & $\begin{array}{c}\text { Alkali çinko }+ \\
\text { kataforez }\end{array}$ & $\begin{array}{c}\text { Alkali çinko- } \\
\text { demir + kataforez }\end{array}$ & $\begin{array}{c}\text { Alkali çinko- } \\
\text { nikel + kataforez }\end{array}$ & $\begin{array}{c}\text { Asitli çinko }+ \\
\text { kataforez }\end{array}$ & $\begin{array}{c}\text { Asitli çinko-nikel } \\
+ \text { kataforez }\end{array}$ \\
\hline F899 & Ad1 / Uygun & Ad1 / Uygun & Ad0 / Uygun & Ad0 / Uygun & Ad0 / Uygun \\
\hline F990 & Ad2 / Uygun değil & Ad2 / Uygun değil & Ad0 / Uygun & Ad0 / Uygun & Ad0 / Uygun \\
\hline
\end{tabular}

Tablo 13. Tuz sisi testi değerlendirme sonuçları

\begin{tabular}{l|c|c|c|c|c}
\hline \multirow{2}{*}{$\begin{array}{l}\text { Döküm } \\
\text { Kodu }\end{array}$} & \multicolumn{5}{|c}{ Kaplama Çeşidi } \\
\cline { 2 - 6 } & $\begin{array}{c}\text { Alkali çinko }+ \\
\text { kataforez }\end{array}$ & $\begin{array}{c}\text { Alkali çinko- } \\
\text { demir + kataforez }\end{array}$ & $\begin{array}{c}\text { Alkali çinko- } \\
\text { nikel + kataforez }\end{array}$ & $\begin{array}{c}\text { Asitli çinko }+ \\
\text { kataforez }\end{array}$ & $\begin{array}{c}\text { Asitli çinko-nikel } \\
+ \text { kataforez }\end{array}$ \\
\hline F899 & Uygun değil & Uygun değil & Uygun değil & Uygun & Uygun \\
\hline F990 & Uygun değil & Uygun & Uygun değil & Uygun & Uygun \\
\hline
\end{tabular}




\subsection{Tuz Sisi Testi}

12-15 $\mu \mathrm{m}$ alkali çinko, alkali çinko-demir, alkali çinkonikel, asitli çinko ve asitli çinko-nikel üzerine 20-25 $\mu \mathrm{m}$ kataforez kaplandıktan sonra ASTM B117 ve DIN EN ISO 9227 numaralı şartnamelere göre yapılan tuz sisi testinin sonuçları Şekil 8'de gösterilmiştir. Uygulanan kaplamanın kabul edilebilmesi için 500 saatlik tuz sisi testi sonrasında lekelenme, bozulma, çatlama, kırılma, şişme, pul şeklinde dökülme, tabakalara ayrılma, boya yapışmasında kopma gibi yüzey bozuklukları olmamalıdır ve parça yüzeyinin maksimum \%5'inde kırmızı pas olmalıdır. Buna göre, asitli çinko + kataforez, asitli çinko-nikel + kataforez kaplı F899 ve F990 sıcak-dövme döküm numuneleri (Şekil 8.d, e, i ve j) ve alkali çinko-demir + kataforez kaplı F990 (Şekil 8.g) testi geçmiştir. Tuz sisi testi değerlendirme sonuçları Tablo 13'te özetlenmiştir (ASTM B117 Standart Method, 1939; International Standard DIN EN ISO 9227, 2006).

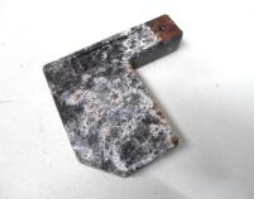

(a)

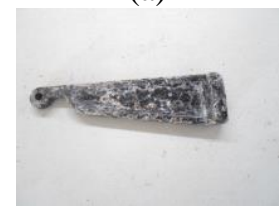

(f)

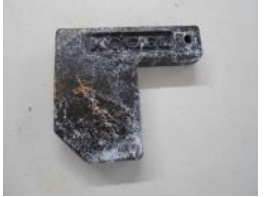

(b)

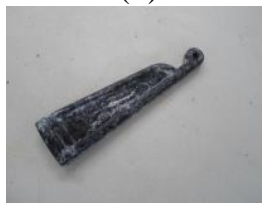

(g)

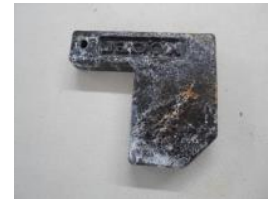

(c)

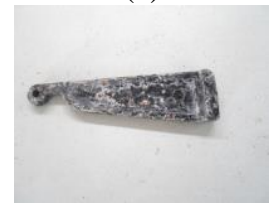

(h)

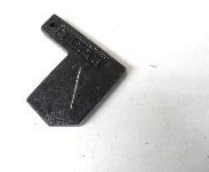

(d)

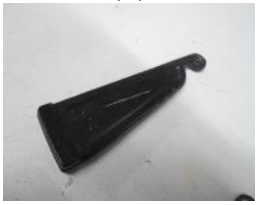

(i)

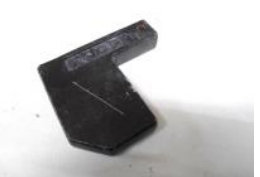

(e)

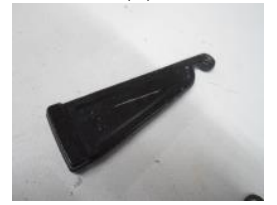

(j)

Şekil 8. Tuz sisi testi sonuçlarl: alkali çinko için (a) F899 ve (f) F990, alkali çinko-demir için (b) F899 ve (g) F990, alkali çinko-nikel için (c) F899 ve (h) F990, asitli çinko için (d) F899 ve (i) F990, asitli çinko-nikel için (e) F899 ve (j) F990

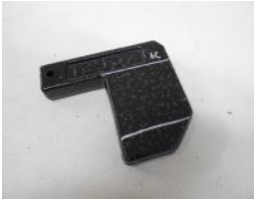

(a)

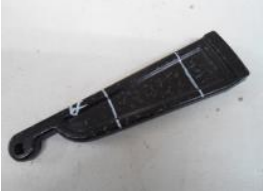

(f)

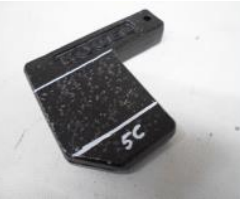

(b)

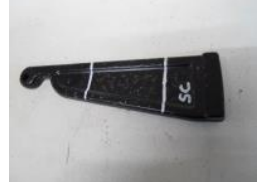

(g)

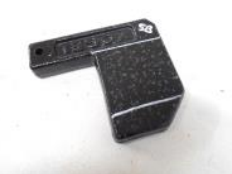

(c)

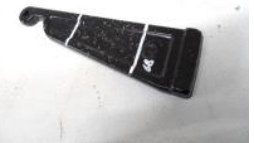

(h)

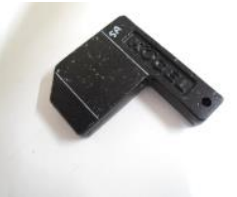

(d)

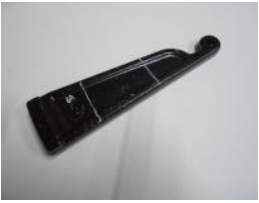

(i)

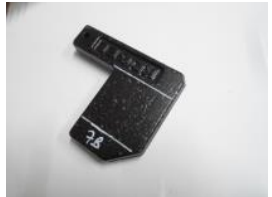

(e)

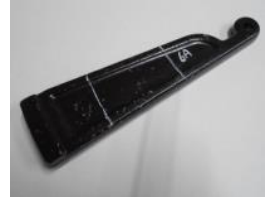

(j)

Şekil 9. Taş çarpma testi sonuçlart: alkali çinko için (a) F899 ve (f) F990, alkali çinko-demir için (b) F899 ve (g) F990, alkali çinkonikel için (c) F899 ve (h) F990, asitli çinko için (d) F899 ve (i) F990, asitli çinko-nikel için (e) F899 ve (j) F990

Tablo 14. Taş çarpma ölçüm sonuçları

\begin{tabular}{l|c|c|c|c|c}
\hline \multirow{2}{*}{$\begin{array}{c}\text { Döküm } \\
\text { Kodu }\end{array}$} & \multicolumn{5}{|c}{ Kaplama Çeşidi } \\
\cline { 2 - 6 } & $\begin{array}{c}\text { Alkali çinko }+ \\
\text { kataforez }\end{array}$ & $\begin{array}{c}\text { Alkali çinko- } \\
\text { demir + kataforez }\end{array}$ & $\begin{array}{c}\text { Alkali çinko- } \\
\text { nikel + kataforez }\end{array}$ & $\begin{array}{c}\text { Asitli çinko }+ \\
\text { kataforez }\end{array}$ & $\begin{array}{c}\text { Asitli çinko-nikel } \\
+ \text { kataforez }\end{array}$ \\
\hline F899 & $6 \mathrm{C} /$ Uygun değil & $5 \mathrm{C} /$ Uygun değil & $5 \mathrm{~B} /$ Uygun değil & $7 \mathrm{~B} /$ Uygun & $7 \mathrm{~B} /$ Uygun \\
\hline F990 & $6 \mathrm{C} /$ Uygun değil & $5 \mathrm{C} /$ Uygun değil & $5 \mathrm{~B} /$ Uygun değil & 7B / Uygun & $7 \mathrm{~B} /$ Uygun \\
\hline
\end{tabular}




\subsection{1. Çevrimsel Korozyon Testi}

12-15 $\mu \mathrm{m}$ alkali çinko, alkali çinko-demir, alkali çinkonikel, asitli çinko ve asitli çinko-nikel üzerine kataforez kaplanan numunelere PV1200 numaralı şartnameye göre çevrimsel korozyon testi yapılmış ve sonuçlar Şekil 10'da sunulmuştur. Uygulanan kaplamanın kabul edilebilmesi için 8 çevrimden sonra çevrimsel korozyon testi sonucu kabarma, base metal korozyon, boya yapışmasında kopma gibi yüzey bozuklukları olmamalıdır ve yapışma kaybı $\mathrm{d} \leq 1,5 \mathrm{~mm}$ olmalıdır. Buna göre, asitli çinko + kataforez ve asitli çinko-nikel + kataforez kaplı F899 ve F990 s1cak-dövme döküm numunelerinin (Şekil 10.d, e, i ve j) testi geçtiği belirlenmiştir. Çevrimsel korozyon testi değerlendirme sonuçları Tablo 15'te verilmiştir (Test standart PV1200, 2004).

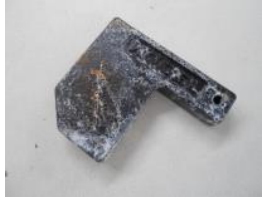

(a)

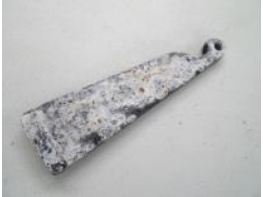

(f)

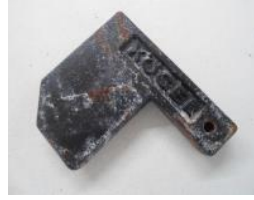

(b)

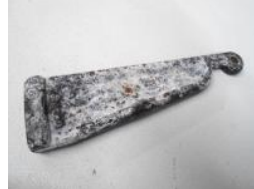

(g)

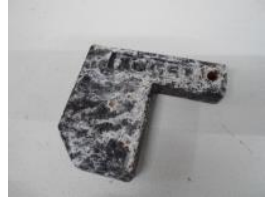

(c)

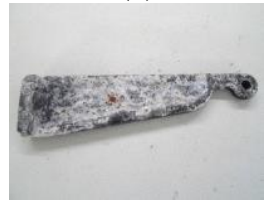

(h)

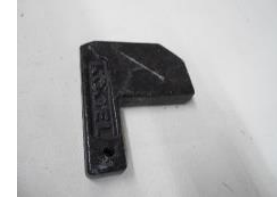

(d)

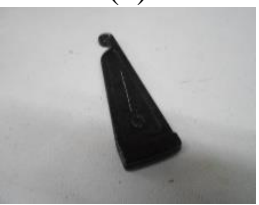

(i)

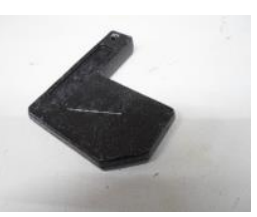

(e)

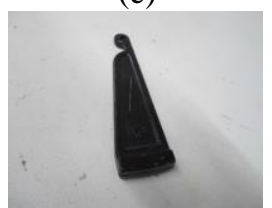

(j)

Şekil 10. Çevrimsel korozyon testi sonuçları: alkali çinko için (a) F899 ve (f) F990, alkali çinko-demir için (b) F899 ve (g) F990, alkali çinko-nikel için (c) F899 ve (h) F990, asitli çinko için (d) F899 ve (i) F990, asitli çinko-nikel için (e) F899 ve (j) F990

Tablo 15. Çevrimsel korozyon değerlendirme sonuçları

\begin{tabular}{l|c|c|c|c|c}
\hline \multirow{2}{*}{ Döküm } & \multicolumn{5}{|c}{ Kaplama Çeşidi } \\
\cline { 2 - 6 } & $\begin{array}{c}\text { Alkali çinko }+ \\
\text { kataforez }\end{array}$ & $\begin{array}{c}\text { Alkali çinko- } \\
\text { demir + kataforez }\end{array}$ & $\begin{array}{c}\text { Alkali çinko- } \\
\text { nikel + kataforez }\end{array}$ & $\begin{array}{c}\text { Asitli çinko }+ \\
\text { kataforez }\end{array}$ & $\begin{array}{c}\text { Asitli çinko-nikel } \\
+ \text { kataforez }\end{array}$ \\
\hline F899 & Uygun değil & Uygun değil & Uygun değil & Uygun & Uygun \\
\hline F990 & Uygun değil & Uygun değil & Uygun değil & Uygun & Uygun \\
\hline
\end{tabular}

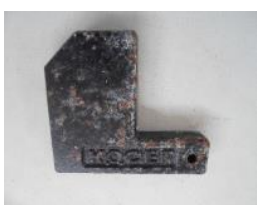

(a)

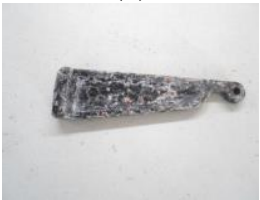

(f)

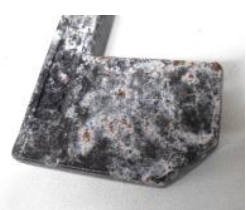

(b)

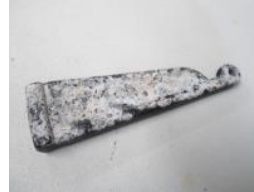

(g)

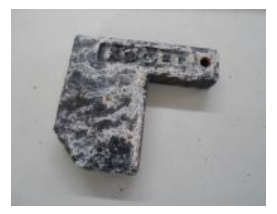

(c)

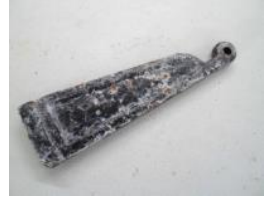

(h)

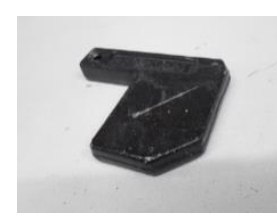

(d)

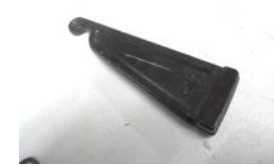

(i)

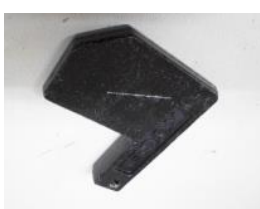

(e)

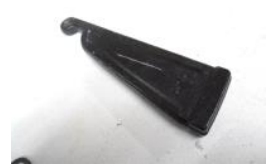

(j)

Şekil 11. Scab korozyon testi sonuçlarl: alkali çinko için (a) F899 ve (f) F990, alkali çinko-demir için (b) F899 ve (g) F990, alkali çinko-nikel için (c) F899 ve (h) F990, asitli çinko için (d) F899 ve (i) F990, asitli çinko-nikel için (e) F899 ve (j) F990 
Tablo 16. Scab korozyon değerlendirme sonuçları

\begin{tabular}{l|c|c|c|c|c}
\hline \multirow{2}{*}{$\begin{array}{l}\text { Döküm } \\
\text { Kodu }\end{array}$} & \multicolumn{5}{|c}{ Kaplama Çeşidi } \\
\cline { 2 - 6 } & $\begin{array}{c}\text { Alkali çinko }+ \\
\text { kataforez }\end{array}$ & $\begin{array}{c}\text { Alkali çinko- } \\
\text { demir + kataforez }\end{array}$ & $\begin{array}{c}\text { Alkali çinko- } \\
\text { nikel + kataforez }\end{array}$ & $\begin{array}{c}\text { Asitli çinko }+ \\
\text { kataforez }\end{array}$ & $\begin{array}{c}\text { Asitli çinko-nikel } \\
+ \text { kataforez }\end{array}$ \\
\hline F899 & Uygun değil & Uygun değil & Uygun değil & Uygun & Uygun \\
\hline F990 & Uygun değil & Uygun değil & Uygun değil & Uygun & Uygun \\
\hline
\end{tabular}

\section{Sonuç}

Metal ve metal alaşımlarının yüzeylerinin korozyona karşı korunma işlemi büyük bir önem teşkil etmektedir. Bahsi geçen koruma işlemi ise kaplamalar yardımıyla gerçekleştirilmektedir. $\mathrm{Bu}$ çalışmanın ilk aşamasında, sıcak-dövme döküm parçalara kumlama işlemi öncesi yapılan yağ alma işleminin uygunluğu mürekkep testi ile incelenmiştir. Buna göre, 5 ve 10 dakikalık yă alma işlemine tabi tutulan numunelerin testi geçmediği ancak 20 dakikalık yağ alma işlemi yapılan tüm numunelerin mürekkep testini geçtiği belirlenmiştir. Sicak yă̆ alma işlemi sonrası numunelere yapılan kumlama işleminin uygunluğu hogabom testi ile kontrol edilmiş ve 10 dakika kumlama işlemi yapılan tüm numunelerin testi geçtiği belirlenmiştir. Kumlama işlemi sonrası alkali çinko, alkali çinko-demir, alkali çinko-nikel, asitli çinko ve asitli çinko-nikel kaplama öncesi yapılan ultsonik yağ alma işleminin uygunluğu şok testi ile analiz edilmiş ve 10 dakikalık ultrasonik yağ alma işlemi yapılan tüm numunelerin testi geçtiği belirlenmiştir. Ultrasonik yağ alma işlemi sonrası çinko-esaslı kaplama uygulanan numunelerin kaplama kalınlıklarının 12-15 $\mu \mathrm{m}$ aralığında olduğu X-1şını kırınım laminografi cihazı ölçümü ile ispatlanmıştır. Çinko-esaslı kaplama üzerine fosfat kaplanan numunelere SEM analizi uygulanmış ve tüm numunelerin istenilen görünümde ve fosfat kristal büyüklüğü 3-6 $\mu$ m olacak şekilde kaplandığ gözlenmiştir. Ayrıca fosfat kristallerinin alkali çinko kaplanan yüzeylerde yatay, asitli çinko kaplanan yüzeylerde dikey olduğu belirlenmiştir. Son aşamada, fosfat kaplama üzerine kataforez kaplama yapılmıştır. Pull-off adhezyon testi sonucuna göre, tüm numuneler için kataforez kaplamanın çinko kaplamaya tutunumunun uygun olduğu tespit edilmiştir. Uygulanan test sonuçlarına göre, sıcak-dövme döküm paçalarının korozyon direncini artırmak için en uygun kaplamanın 12-15 $\mu \mathrm{m}$ asitli çinko, asitli çinko-nikel + kataforez kaplama olduğu belirlenmiştir. Ancak asitli çinko-nikel kaplama maliyet açısından asitli çinko kaplamaya göre daha pahalı bir kaplama olduğu için sıcak-dövme döküm parçaların korozyon direnci göz önüne alındığında asitli çinko üzerine kataforez kaplamanın tercih edilebileceği öngörülmüştür.

\section{Teşekkür}

Bu çalışma, Uzman Kataforez Yüzey Kaplama San. ve Tic. A.Ş. firması tarafından yürütülen TÜBİTAK 3180632 nolu projenin bir parçası olarak desteklenmiş olup, yazarlar TÜBİTAK ve Uzman Kataforez Yüzey Kaplama San. ve Tic. A.Ş. firmasına teşekkürü bir borç bilirler.

\section{Kaynakça}

Adhesion Test 50765 (1990). Metallic Material Surface Treatments Electrolytic Plating and Chemical Coating Heat Shock Adhesion Test.

Amadeh, A., Pahlevani, B., \& Heshmati-Manesh, S. (2002). Effects of rare earth metal addition on surface morphology and corrosion resistance of hot-dipped zinc coatings. Corrosion Science, 44(10), 2321-2331.

ASTM B117 Standart Method (1939). Salt Spray (Fog) Testing.

ASTM D4541 Standart test method. (2017). Pull-Off Strength of Coating Using Portable Adhesion Testers.

Chemetall Gardobond AP9809 TDS (2017), Liquid, phosphorous-free pre-treatment for multi-metal applications.

Chemetall Gardobond 24T TDS (2018), A manganese modified low zinc phosphating process for steel and galvanised steel materials.

Chemetall Gardolene V 6513 TDS (2017), Activating pre-rinsing agent for metal surfaces applied by immersion or spray prior to phosphating.

Ekinoks Kimya Alukleen CV TDS (2017), Alüminyum, bakır, pirinç, zamak gibi metal ve alaşımlarının yüzey temizliği prosedürü."”

Ekinoks Kimya Cleanox E TDS (2019), Metal sanayi ve otomobil endüstrisinde elektrolitik yă̆ alma işlemi prosedürü.

Ekinoks Kimya Cleanox 1972 TDS (2018), Metal sanayi ve otomobil endüstrisinde demir, çelik, alüminyum ve çinko yüzeyler için kullanılan kuvvetli alkali yă̆ alma malzemesinin daldırma ve püskürtme yöntemiyle uygulanma prosedürü.

Eser Kimya ES/FE 36 TDS (2017), Siyanürsüz alkali çinkodemir kaplama prosesi.

Eser Kimya ES/F1 TDS (2017), Siyanürsüz alkali çinko kaplama prosesi.

Eser Kimya ES/RKR TDS (2018), Asitli çinko kaplama prosesi.

Eser Kimya ES/RKR-NI TDS (2018), Asit çinko-nikel kaplama prosesi.

Eser Kimya ES/ZN-NI Plus TDS (2017), Alkali çinko-nikel kaplama prosesi.

Fiat Auto Normazione Material Standart 50470 (2005). Water Resistance Test for Decorations and Paints.

Fiat Auto Normazione Material Standart 50493/04. (2011). Determination of the resistance of organic coatings to the propagation of bubble under skin corrosion (scab in door).

Fujita, S., \& Mizuno, D. (2007). Corrosion and corrosion test methods of zinc coated steel sheets on automobiles. Corrosion Science, 49(1), 211-219.

Ganesan, S., Prabhu, G., \& Popov, B. N. (2014). Electrodeposition and characterization of $\mathrm{Zn}-\mathrm{Mn}$ coatings for 
corrosion protection. Surface and Coatings Technology, 238, 143-151.

International Standard DIN EN ISO 9227. (2006). Corrosion tests in artificial atmospheres - Salt spray tests.

International Standard ISO 3497. (2001). Metallic coating Measurement of coating thickness - X-ray spectrometric methods.

International Standard ISO 8296 (2003), Plastics - Film and sheeting - Determination of wetting tension. Geneva.

International Standard SAE J400. (2012). Surface vehicle recommended practice.

Kılınç, M. (2019). Kataforez kaplama üzerine solvent bazlı ve su bazlı lamelli kaplama uygulamalarl ile oluşacak dubleks kaplamanin korozyon ve ömür testine etkisinin incelenmesi, Yüksek Lisans Tezi, Eskişehir Teknik Üniversitesi, Fen Bilimleri Enstitüsü, Eskişehir.

Lawrance, J. D. (1963). Electroplating Engineering Handbook, 4th ed., New York.

NOF Metal Coatings Group. (2017). GEOMET 321/500 Technical manuel (EN).

Polat, B. D., Timur, I. S., Keles, Ö. (2013). Çinko-alüminyum alaşımından üretilmiş döküm parçalarının korozyon direncine bakır kaplama proseslerinin etkisi. Gazi Üniversitesi Fen Bilimleri Dergisi Part:C, Tasartm Ve Teknoloji, 1(3), 103-113.

Ppg CP458A TDS (2017), Electrocoating Process.
Ppg Powercon P6200 TDS (2018), Electrocoating Process.

Ramanauskas, R., Quintana, P., Maldonado, L., Pomés, R., \& Pech-Canul, M. A. (1997). Corrosion resistance and microstructure of electrodeposited $\mathrm{Zn}$ and $\mathrm{Zn}$ alloy coatings. Surface and Coatings Technology, 92(1-2), 16-21.

Test standart PV1200. (2004). Testing of resistance to environmental cycle test $(+80 /-40){ }^{\circ} \mathrm{C}$.

Uyanı,, M. (2012). SiC nanopartikül ilaveli asitli çinko kaplama banyolarında yapılan kaplamaların malzemenin korozyon direnci ve mekanik özelliklerine etkisinin araştırılması, Yüksek Lisans Tezi, Yıldız Teknik Üniversitesi, Fen Bilimleri Enstitüsü, İstanbul.

Uzman Kataforez Yüzey Kaplama San. Ve Tic. A.Ş. (2019), Yüzey temizleme, çinko ve katarofez kaplama prosedürleri raporlarl.

Volvo car corporation test standart VCS 5740,1049. (2011). Phosphating.

Y1lmaz, E. (2013). Electroplated coating of cast steel and zamak parts by acidic zinc nickel, Master Thesis, Marmara University, Institute for Graduate Studies in Pure and Applied Sciences, İstanbul.

Zaki N., Frederick Gumm Chemical Company, Inc. (1993). Zinc Alloy Plating, Surface Engineering (Introduction) Volume 5; ASTM. 